\title{
HELICALLY COILED CARBON NANOTUBES
}

\author{
M. Damnjanović, I. Milošević \\ University of Belgrade, Faculty of Physics, Belgrade 11001, POB 44, Serbia
}

\begin{abstract}
Helically coiled carbon nanotubes are frequently synthesized, with well elaborated techniques of growth. This paper is a study of stability and conductivity of these configurations within simple theoretical model followed by the numerical approach.

Keywords: Nanotubes, Carbon, Symmetry, Density functional.
\end{abstract}

\section{INTRODUCTION}

Helically coiled carbon nanotubes were firstly reported [1] in 1994. Meanwhile, experimental studies of growth and various properties were performed [2], but no theoretical and numerical aspects were treated. Here we propose a simple model of configuration, and use its symmetry to show examined stability and conducting properties of such tubes.

After introducing the model in Section 2, we derive its symmetry group (Section 3 ) and use it in the numerical density functional study of stable configurations (Section 4) and conducting properties (Section 5).

\section{MODEL OF CONFIGURATION}

The first models [2] of helically coiled carbon nanotubes (HCCNTs) involve pentagon-heptagon pairs to produce additional curvature of coil. However, appearance of unobserved knees, and a very restrictive number of configurations allowed by this model, inspire us to propose a simpler model, with hexagons only. They are slightly deformed to enable helical coil. In fact, our model can be imagined as a straight single-wall carbon nanotube (SWCNT) pulled on the helix (with radius $R$ and inclination angle $\chi$ ) around $Z$-axis, such that helix becomes curved SWCNT axis.

We assume that this deformation is homogeneous along the helix, but not around the tube: the parts of tube closer to the helix axis are slightly squeezed, while the outer parts are stretched. The perpendicular to $Z$-axis through the center of intersection of the nanotube with $Z=0$ plane is $X$-axis. The angle $\varphi_{0}$ between this and $x$-axis in SWCNT coordinate system [3] fixes another degree of freedom, relative position of the tube and helix.

\section{SYMMETRY}

Let's recall that the whole SWCNT is determined by its single atom, and symmetry group [3], which is a line group [4] with translational period $a$, screw-axis, pure rotations and $U$-axis coinciding with nanotube $\mathrm{x}$-axis (also, mirror planes for achiral tubes). When pulled on the helix, the elementary cell of SWCNT becomes the minimal part from which HCCNT is built by the action of its symmetry group. The later is a line group $\boldsymbol{T}_{Q}(F) \boldsymbol{C}_{l}$ of the first family, where the screw axis is defined by the Koster deformation $\left(C_{Q} \mid F\right)$ (rotation for $2 \pi / Q$ around $Z$-axis followed by translation for $F$ along $Z$-axis). Only for special position $\varphi_{0}=0$ there is an additional $U$-axis (rotation for $\pi$ ) coinciding with $\mathrm{X}=\mathrm{x}$ axis; then the symmetry is from the fifth line group family, $\boldsymbol{T}_{Q}(F) \boldsymbol{D}_{1}$.

It remains to calculate $Q$ and $F$. As (coiled) translational period $a$ of SWCNT is the generating part of HCCNT, the lengths of its vertical and horizontal projections are $\mathrm{F}$ and $2 \pi R / Q$, and we find:

$$
\begin{aligned}
& F=a \sin \chi, \\
& Q=2 \pi R / a \cos \chi
\end{aligned}
$$

The number of the atoms in this generating part is [3]:

$$
N=\left(2 n_{1} n_{2}+2\left(n_{1}+n_{2}\right)^{2}\right) / \operatorname{GCD}\left(2 n_{1}+n_{2}, n_{1}+2 n_{2}\right),
$$

which varies from tens to thousands, and increases with the tube diameter.

It should be stressed out that $Q$ can be irrational. In that case HCCNT does not possess the translational periodicity. Only when rational, i.e. $Q=q / r$ for some integers q and r, HCCNT is translationally periodic with period 
$A=q F$.

(4)

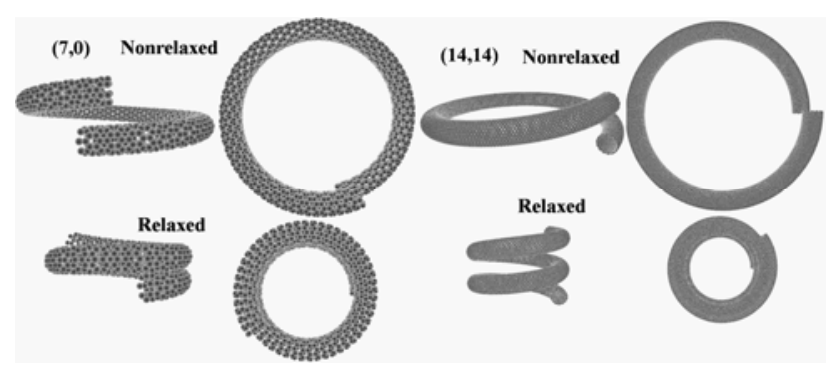

Figure 1. Relaxed and nonrelaxed structures of HCCNTS $(7,0)$ and $(14,14)$.

\section{RELAXATION PARAMETERS}

The introduced assumptions of the model enable simple geometrical derivation of the coordinates of all the atoms. Here we omit this straightforward but lengthy calculation. We only want to single out the independent parameters. To this end, we recall that SWCNT is described by four parameters (three coordinates $\boldsymbol{r}_{0}$ of an atom, and the period $a$ ), helical coil by two (radius $R$ and inclination angle $\chi$ ), and position of the tube on the helix by angle $\varphi_{0}$. Hence, there are seven parameters characterizing helically coiled nanotube.

Knowing this, we can start the numerical study. The first goal is to find out relaxed configurations, i.e. the value of the above parameters minimizing the energy of HCCNT. We use the density functional tight binding approach, which for carbon based systems enable density functional precision still allowing full symmetry implementation to reduce calculations. This is performed by the numerical code POLSym [5].

We considered approximately 50 HCCNTs with generic SWCNTs with various chiralities, and diameters varying from $0.5 \mathrm{~nm}$ to $1.2 \mathrm{~nm}$. In the relaxation procedure we started with the initial configuration corresponding to the relaxed SWCNT coiled in a way that helix radius $\mathrm{R}$ was five times greater than the SWCNT radius, while the inclination angle $\chi$ gave helix step three times greater than SWCNT radius. This choice is made as an average of the shapes of the samples in the literature [2]. It is interesting that procedure converged rapidly, in less than 300 steps, meaning that this initial configuration was not far from the stable one. However, it is significant that no rule can be found for the relaxed values of the coil parameters $\mathrm{R}$ and $\chi$. For majority of the tubes, relaxed radius $\mathrm{R}$ is greater than initial, while angle $\chi$ is increased in the relaxation. Still, there are many exceptions of all kinds (see examples in Fig. 2.)

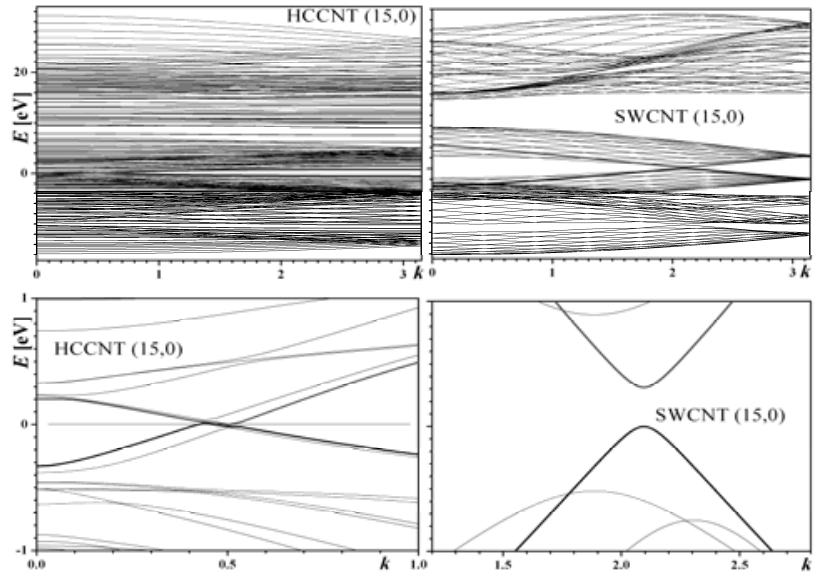

Figure 2. Electron bands of HCCNT and SWCNT $(15,0)$. Roughly similar structures differ near Fermi level (second row): HCCNT is metallic and SWCNT quasi metallic.

\section{ELECTRONIC PROPERTIES}

Finally, we calculated electronic band structure of the relaxed nanotubes. Obviously, due to a great (or infinite in incommensurate cases) translational period, one must use helical quantum numbers [3]. Firstly, helical momentum $\mathrm{k}$ is canonically conjugated to the helical coordinate generated by the screwaxis $\boldsymbol{T}_{Q}(F)$, and takes values from the helical Brillouin zone $(-\pi / F, \pi / F]$. The remaining angular momentum is described by the quantum number $\mathrm{m}$; however, as the pure rotational axis is trivial $\boldsymbol{C}_{1}$ it takes only one value, $m=0$ (and will be omitted in the following). Only when $\varphi_{0}=0$, when $\mathrm{x}$-axis (being $\mathrm{U}$-axis of SWCNT) coincides with X-axis, there is additional parity quantum number, taking two values + and -. Also, this symmetry reduces irreducible domain to the half $[0, \pi / F]$ of the Brillouin zone.

Thus the electronic bands are functions $\mathrm{E}(\mathrm{k})$ over Brillouin zone or irreducible domain. They are assigned by the same quantum number $\mathrm{m}=0$, meaning that they cannot cross. Only for $\varphi_{0}=0$, two bands with opposite $U$ parity can join at the end points 0 and/or $\pi / F$. Recall that armchair SWCNTs are metallic, while the other ones with $n_{1}-n_{2}$ divisible by 3 are quasi metallic, because the crossing bands in the armchair tubes have different parity, while, in other ones, all the quantum numbers are the same and a tinny gap appears.

Calculated band structures have seemingly similar global shape as the band structures of SWCNTs. However, density of the states is significantly larger in HCCNTs. Most of them are conducting, but the armchair ones are quasi metallic. Therefore, HCCNTs are foreseen as good conductors. 


\section{SUMMARY}

A sample of 50 helically coiled nanotubes is analyzed by the density functional numerical methods, using symmetry. No pentagon-heptagon pairs are needed for stability. Most of them are conductive with a high density of states on the Fermi level.

\section{ACKNOWLEDGEMENTS}

The authors acknowledge the funding of Serbian Ministry of Science (Project No. ON141017) and Swiss National Science Foundation (SCOPESIZ73Z0-128037/1).

\section{REFERENCES}

[1] X. B. Zhang, X. F. Zhang, D. Bernaerts, G. Van Tendeloo, S. Amelinckx, J. Van Landuyt, V. Ivanov, J.B. Nagy, Ph. Lambin, and A.A., Lucas, Europhys. Lett. 27 (1994) 141.

[2] D. Fejes and K. Hernadi, Materials 3 (2010) 2618.

[3] M. Damnjanović, I. Milošević, T. Vuković and R. Sredanović, Phys. Rev. B 60 (1999) 2728-39

[4] M. Damnjanović, I. Milošević, Line Groups in Physics (Springer-Verlag, Berlin, 2010).

[5] M. Damnjanović, I. Milošević, T. Vuković, E. Dobardžić and B. Nikolić, in Applied Physics of Nanotubes; Fundamentals of Theory, Optics and Transport Devices, eds. S. V. Rotkin and S. Subramoney (Springer-Verlag, Berlin, 2005).

$\operatorname{sos} 2$

\section{ХЕЛИКАЛНО САВИЈЕНЕ УГЉЕНИЧНЕ НАНОТУБЕ}

Сажетак: Хеликално савијене угљеничне нанотубе су веома честе и постоје добро разрађени методи њихове синтезе. Овај рад осветљава, теоријски и нумерички, стабилност и проводност оваквих конфигурација.

Кључне речи: нанотубе, угљеник, симетрија, функционал густине. 